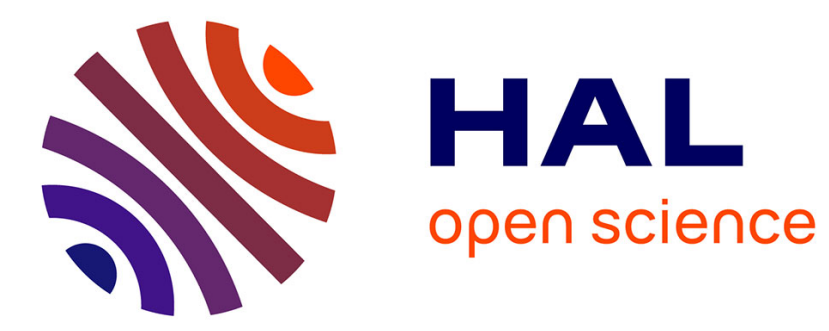

\title{
Experimental Study of the Transformation-Induced Plasticity in a Cr-Ni-Mo-Al-Ti Steel
}

\author{
J.-C. Videau, Georges Cailletaud, André Pineau
}

\section{To cite this version:}

J.-C. Videau, Georges Cailletaud, André Pineau. Experimental Study of the Transformation-Induced Plasticity in a Cr-Ni-Mo-Al-Ti Steel. Journal de Physique IV Proceedings, 1996, 06 (C1), pp.C1-465C1-474. 10.1051/jp4:1996145 . jpa-00254177

\section{HAL Id: jpa-00254177 https://hal.science/jpa-00254177}

Submitted on 1 Jan 1996

HAL is a multi-disciplinary open access archive for the deposit and dissemination of scientific research documents, whether they are published or not. The documents may come from teaching and research institutions in France or abroad, or from public or private research centers.
L'archive ouverte pluridisciplinaire HAL, est destinée au dépôt et à la diffusion de documents scientifiques de niveau recherche, publiés ou non, émanant des établissements d'enseignement et de recherche français ou étrangers, des laboratoires publics ou privés. 


\title{
Experimental Study of the Transformation-Induced Plasticity in a Cr-Ni-Mo-Al-Ti Steel
}

\author{
J.-C. Videau*,**, G. Cailletaud* and A. Pineau* \\ * Centre des Matériaux de l'Ecole des Mines de Paris, URA 866 du CNRS, BP. 87, 91003 Evry cedex, \\ France \\ ** Centre Technique des Matériaux et Structures (CTMS), CEAT, 23 avenue Guillaumet, \\ 31056 Toulouse cedex, France
}

\begin{abstract}
This paper shows experimental results concerning the martensitic transformation and the transformation-induced plasticity under multiaxial loading. The material investigated is a Cr-Ni-Mo-Al-Ti steel, which is submitted to a $\gamma \rightarrow \alpha^{\prime}$ martensitic phasc transformation under an applied stress. The specimens are thin tubes loaded in tension-torsion. The tests were specially designed to provide information on classical questions related with transformation plasticity and the interaction between applicd stresses and phase transformations in the case of tension-shear loadings: elfect of the applied stresses on $M_{s}$ lemperature, definition of the transformation-induced plasticity (how intensity, direction in stress space, evolution $v s$ phase change), eventual presenee of internal stresses. Some of the answers given by the present study cronfirm the usual assumptions, but the analysis of the tests also reveals new elfects not predicted by the classical theories proposed to quantify the transformation induced plasticity phenomenon.
\end{abstract}

\section{INTRODUCTION}

The thermomechanical behavior of materials undergoing a solid-solid phase transformation under an applied stress has been largely investigated, but is still poorly understood (for a recent review, see e.g.[1]). In particular it is well known that, when a solid material is stbjected to a phase transformation under an applied stress a new mechanical phenomenon, named transformation induced plasticity (TRIP) is observed. TRIP phenomenon is usually attributed to two different mechanisms : (i) stress-assisted nucleation of crystallographic variants which are favourably aligned with the orientation of the applied stress, and (ii) plastic deformation of the parent and product phases. The first mechanism, now currently referred as the Magee effect [2] may be predominant in particular for the martensitic phase transformations in steels (see e.g. [3]). The second mechanism, now currently referred as the Greenwood-Johnson effect [4] is, on the other hand, prevalent for the various diffusion controlled phase transformations occurring in steels (see e.g. [5]).

A number of authors have attempted to develop constitutive equations for TRIP phenomenon which are largely based on the classical equations used in plasticity (see e.g. [6-8]). In these approaches the increment of plasticity due to phase transformation under an applied stress is related to the stress state conditions, the actual value of the amount of phase transformation and to the increment of phase transformation. As a rule these theories are compared to experimental results obtained under uniaxial loading conditions. It is thus impossible to verify completely their adequacy in the absence of experimental studies of phase transformations under multiaxial loading. In a previous paper [9], a general framework was proposed to account for transformation-induced plasticity and viscoplasticity, and for the coupling between the two. A number of questions were related to the expressions used. The main objective of the present study is to contribute to fill in the gap between theories and experiment by reporting recent experimental results obtained on a high strength steel which was submitted to the $\gamma \rightarrow \alpha$ martensitic transformation under tension-shear conditions. 


\begin{tabular}{|l|l|l|l|l|l|l|l|l|l|l|}
\hline $\mathrm{Cr}$ & $\mathrm{Ni}$ & $\mathrm{Mo}$ & $\mathrm{Al}$ & $\mathrm{Ti}$ & $\mathrm{C}$ & $\mathrm{Si}$ & $\mathrm{Mn}$ & $\mathrm{P}$ & $\mathrm{S}$ & $\mathrm{N}$ \\
\hline 12,15 & 9.05 & 2.03 & 0.70 & 0.35 & $<0.01$ & 0.05 & 0.03 & 0.009 & $<0.002$ & 0.0045 \\
\hline
\end{tabular}

Table 1: Nominal composition of the investigated material (weight percent).

\section{MATERIAL}

The material of the study is a $\mathrm{Cr}-\mathrm{Ni}-\mathrm{Mo}$-Al-Ti Maraging steel provided by Aubert et Duval, and referenced as Marval X12. Table 1 shows its composition, which is typical for a high resistance steel with structural hardening. The thermal treatment applied to the bars consists in a solutionizing heat treatment at $840^{\circ} \mathrm{C}$ for 1 hour, followed by air cooling down to room temperature. The structural hardening heat treatment $\left(550^{\circ} \mathrm{C}\right.$ for 4 hours) which is usually given to this material was not applied since this study was only concerned with the $\gamma \rightarrow \alpha$, phase transformation. The transfomation during the cooling period produces martensite only, even at low cooling rattes. X-ray analysis at room temperature demonstrates that the transformation is completely achieved, with no residuil austenite in the material.

This material was chosen due to its excellent guenching capability, the absence of diffusional transformations, and the specificities of its transformation range, with:

- a starting point $\mathrm{M}_{\mathrm{S}}$ at low temperiture (between 150 and $20\left(0^{\circ} \mathrm{C}\right.$ ). High stress levels can then be applied without ("classical") plastic strain and without creep; on the other hand, recovery effects can be neglected in the tests involving a pre-hardening in austenitic phase:

- the full transformation from martensite to austenite.

All these properties, joined to the fact that the material is a stainless steel, made that the same specimen could be used several times: as a matter of fact, several thermal cycles were applied to the specimens, from room temperature to austenitizing temperature, followed by quenching under load, and these successive treatments were supported without apparent damage. It was also tried to apply, after several different cycles, the same conditions as in the first one: the results were reproducible, as indicated in section 5.1.

\section{EXPERIMENTAL, DEVICE}

The tests were made with a servo-hydraulic tension-torsion device, with $\pm 100 \mathrm{kN}$ and $\pm 1200 \mathrm{~m} . \mathrm{N}$ loading capacities. The whole experimental set-up is schematically shown in fig. 1 . The specimens are thin tubes with an external diameter of $19.5 \mathrm{~mm}$ and an internal diameter of $16.5 \mathrm{~mm}$. The length of the cylindrical part is $12 \mathrm{~mm}$.

A tension-torsion extensometer developed at Centre des Materiaux was used. The contact with the specimen consists in two needles only. As they are made from alumina, the extensometer can work at high temperature. A simultaneous measurement of the axial displacement and of the twist angle is obtained in the cylindrical part of the specimen. The pressure applied on the needles was previously calibrated to prevent the extensometer to slip, and at the same time lo avoid local plasticity at the contact point. The tests may then be performed either under suress control, or under displacement control for the pre-hardening sequences).

The specimen is set in a trilobic matiation fumace, producing a homogeneous temperature field on the whole specimen. The cooling is assisted by compressed air, and by water circulation through two rings fixed on the gripping system. The temperature measurement is achieved by means of thermocouples welded on the specimen, and directly imposed by a micro-computer.

All the experimental data (displacement, forces, temperature, ...) are recorded by the micro-computer, for further numerical treatment, in order to finally provide input files to an optimisation code for the numerical simulations. 


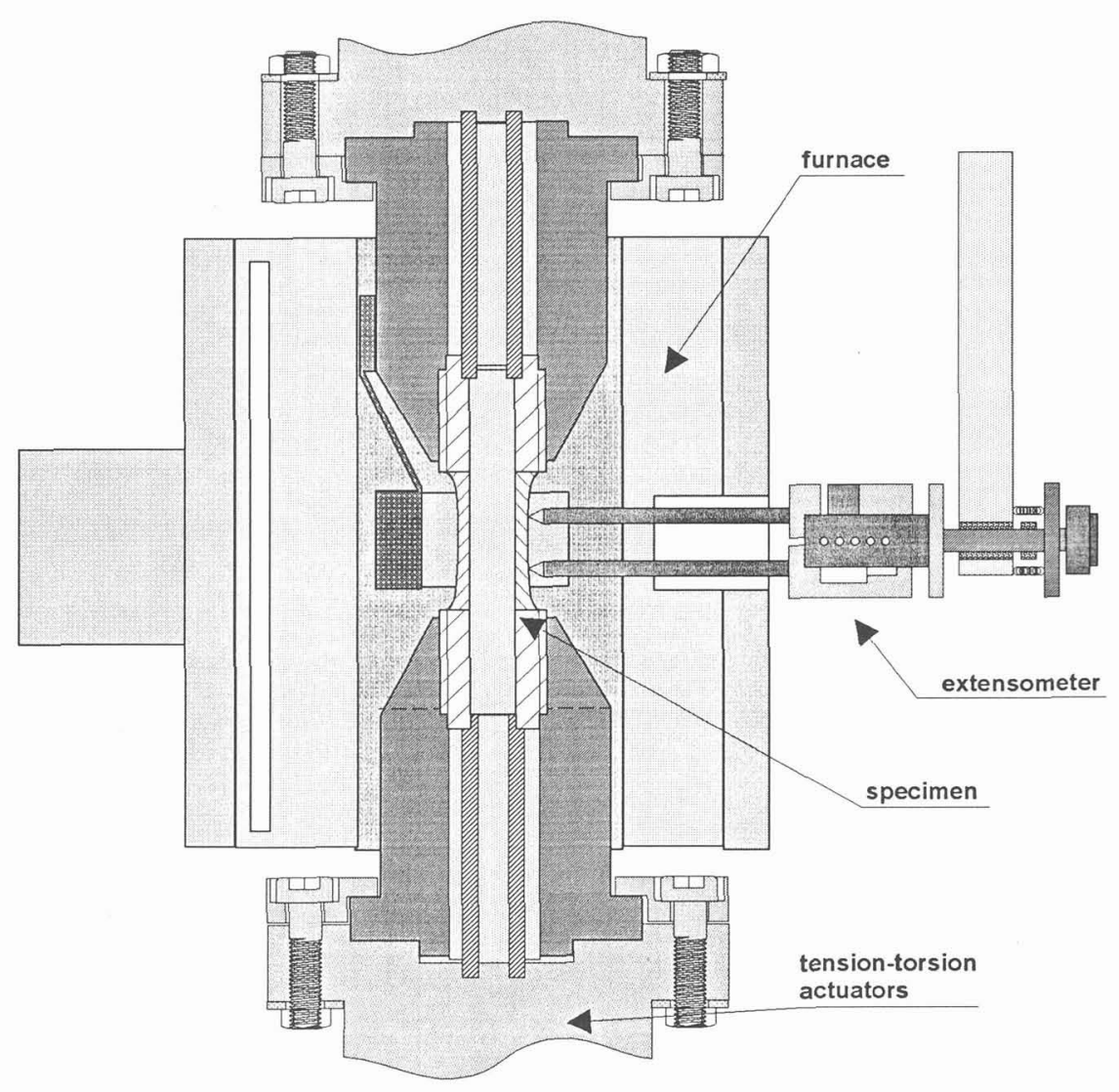

Figure 1: Schematic vicw of the experimental device

\section{TESTING PROCEDURES}

The specimen is first fixed on the testing rig, and equipped with all the measurement system at room temperature. It is heated at a constant temperature rate until $840^{\circ} \mathrm{C}$, then the temperature is kept constant for about 30 minutes in order to solutionize the material in the austenite field. The specimen is then cooled down to room temperature. During this cooling. the loading is quickly applied at $230^{\circ} \mathrm{C}$, the material being still in the austenitic phase. According to the type of test, the loading is kept constant, or a loading step is made during the transformation, in order to evaluate the internal stresses. This temperature of $230^{\circ} \mathrm{C}$ is high enough to avoid the formation of stress induced martensite when the load is applied, and low enough to reduce the possible creep effects for the highest loadings, which are around the apparent yield stress of the austenite phase. This yield stress (about $180 \mathrm{MPal}$ ) was previously characterized by pure tension and pure torsion tests. These tests may thus be regarded as anisothermal creep tests, or as dilatometric tests (partially) under load.

Five different types of loadings were applied. In each case, the stress level is evaluated in terms of von Mises equivalent:

- tension under $30,50,90,120,150 \mathrm{MPa}$,

- torsion under $30,50,90,120,150 \mathrm{MPa}$,

- tension-torsion under $30,50,90,120,150 \mathrm{MPa}$,

- compression under $30,50,90,120 \mathrm{MP}$,

- compression-torsion under $50,70,90,120 \mathrm{MPa}$. 
For the tension-torsion (resp. compression-torsion) tests, the ratio $\sigma_{11} / \sigma_{12} \sqrt{3}$ is maintained equal to 1 (resp. -1). For all the stress levels investigated, the material remained in the elasticity domain during the loading.

All the tests were at least performed twice in order to check the reproducibility of the experiment. In fact, no significant discrepancy was noted, for any kind of loading (one- or two-dimensional), for any specimen, and any thermal cycle.

As previously stated, some of the tests involved a load step during the transformation. This technique, known as "dip test", consists in a total or partial unloading, after preliminary flow at the first loading level. The subsequent flow intensity and sign give information on the actual value of the "neutral state" of the material, resulting from the first part of the loading. Five tests were made under torsion, with an initial stress level of $120 \mathrm{MPa}$, and followed by unloadings to (), 30 and 60 MPa. In addition, a tension test was also performed, with a first level at $120 \mathrm{MPa}$ followed by a total unloading.

Two specific dilatometric tests and three transformation tests under $50 \mathrm{MPa}$ and $90 \mathrm{MPa}$ torsion loadings were also added to the data base. For these tests, a torsion prehardening is applied when the specimens are in the austenitic phase. For that purpose, the cooling is stopped for a while at $200^{\circ} \mathrm{C}$, and several mechanical cycles are applied. The tests follow then their normal course, id est loading, and cooling. Provided the analysis is made cirefully, they allow us to study the interaction between classical plasticity and transformation induced plasticity, through the intuence of hardening observed in classical plasticity (isotropic and kinematic hadening) on transformation plasticity.

Each specimen was used for a maximum of 10 themal cycles $\left(20^{\circ} \mathrm{C}-840^{\circ} \mathrm{C}-20^{\circ} \mathrm{C}\right)$. Neither oxidation nor damage was found on the specimens. The first and the last cycles were made without applied load, so that the classical dilatometric characteristics were determined (thermal expansion coefficients, variation of the specific volume during phase transtormation), and also the kinetics of the martensitic transformation.

\section{EXPERIMENTAL RESULTS}

The main experimental results are now reported. An attempt is made to exhibit clearly the principal characteristics of the transformation, and to present the results in an unbiased way. As indicated below, the complete modeling of the reported observations is in progress and will be presented in a further paper.

\subsection{Influence of the applied stress on the onset of the martensitic transformation}

Figure 2 shows the dilatometric curves obtained on one specimen, which supported several thermal cycles, under various tensile stresses. The successive loading levels were $0 \mathrm{MPa}$ at the first cycle, then $30 \mathrm{MPa}$, $50 \mathrm{MPa}, 90 \mathrm{MPa}, 120 \mathrm{MPa}, 150 \mathrm{MPa}$, the last cycle being performed under zero load. Thanks to this procedure, the memory effect due to the themomechanical history can be characterized: the maximum strain at high temperature exhibits a low shift. It must be noted that the values of $\mathrm{M}_{\mathrm{s}}$ and of the volume change obtained for the last cycle remain consistent with the intial one. During the cooling, the application of the load can be seen by a small increase of the tolal strain at $230^{\circ} \mathrm{C}$. For $150 \mathrm{MPa}$, the martensitic transformation starts at a temperature $\mathrm{M}_{s}=18()^{\circ} \mathrm{C}$, whereas it starts around $150^{\circ} \mathrm{C}$ with no applied load. The variation of $\mathrm{M}_{\mathrm{s}}$ versus stress is linear in the $0-120 \mathrm{MPa}$ range, with a slope of $0.165^{\circ} \mathrm{C} . \mathrm{MPa}^{-1}$.

A similar behaviour was noticed for the other types of loadings, although less pronounced. Using von Mises equivalent stress $\sigma_{c q}$ such as $\sigma_{a !}^{2}=\sigma_{11}{ }^{2}+3 \sigma_{12}{ }^{2}$, the values of the slope are : (i) for tensile loading, $\mathrm{dM}_{\mathrm{s}} / \mathrm{d} \sigma_{\mathrm{eq}}=0.165^{\circ} \mathrm{C} . \mathrm{MPa}^{-1}$, (ii) for torsional loading, $\mathrm{dM}_{\mathrm{s}} / \mathrm{d} \sigma_{\mathrm{eq}}=0.059^{\circ} \mathrm{C}_{\mathrm{MPa}} \mathrm{MP}^{-1}$, (iii) for tension-torsion loading, $\mathrm{dM}_{\mathrm{s}} / \mathrm{d} \sigma_{\mathrm{cq}}=0.141^{\circ} \mathrm{C} . \mathrm{MPa}^{-1}$.

These results clearly show that the variation of the $M_{s}$ temperature is controlled not only by the $\gamma \rightarrow \alpha^{\prime}$ volume change, but also by the shear components associated with the phase transformation, as modeled in $[10]$. 


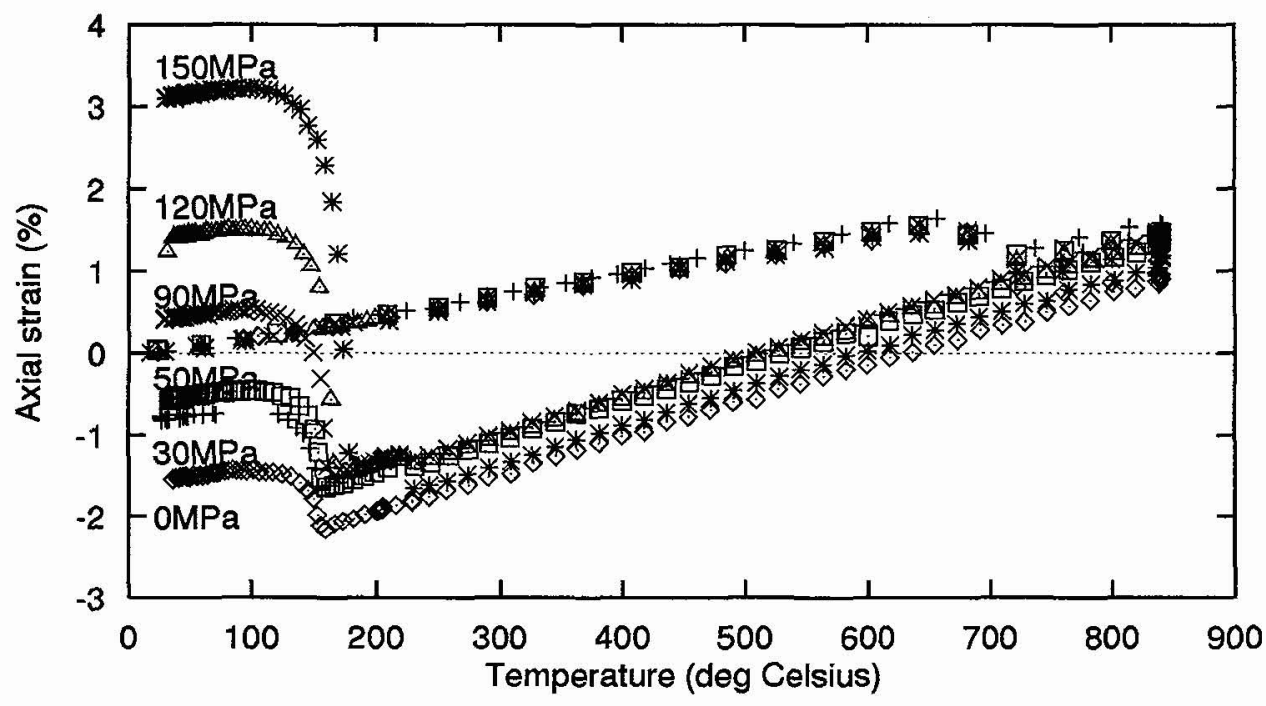

Figure 2: Dilatometric curves under tension lokding

\subsection{Influence of the applied stress on the amount of transformation-induced plasticity}

The amount of transformation plasticity for $100 \%$ of phase transformation can be read from the dilatometric curves, when room temperature is reached. This value non linearly depends on the applied stress. The ranking of the different loading types is illustrated in fig. 3 , which shows that the stress sensitivity is the higher for tension loadings, then for tension-torsion, torsion, compression-torsion and pure compression. In fact, the three first cases do not present a large difference, for the same von Mises equivalent, but their efficiency is much higher than the latter ones. The amount of transformation-induced plasticity observed during the tests was $2 \%$ for a 150 MPa tensile stress. The ratio between the TRIP for $120 \mathrm{MPa}$ in tension and compression is 2.7. Defining von Mises exuivalent in terms of transformation-induced plastic strain $\varepsilon_{\varepsilon q}^{p t}$ by means of $\left(\varepsilon_{\mathrm{cq}}^{\mathrm{pl}}\right)^{2}=\left(\varepsilon_{11}^{\mathrm{pt}}\right)^{2}+(4 / 3)\left(\varepsilon_{12}^{\mathrm{pl}}\right)^{2}$, the values of the coefficient $\mathrm{K}=\mathrm{d} \varepsilon_{\mathrm{cq}}^{\mathrm{pl}} / \mathrm{d} \sigma_{\mathrm{eq}}$ are respectively: (i) $\mathrm{K}=5.410^{-5} \mathrm{MPa}^{-1}$ for low tensile stresses, (ii) $\mathrm{K}=3.410^{-5} \mathrm{MPa}^{-1}$ for low compressive stresses, (iii) $\mathrm{K}=21.910^{-5} \mathrm{MPa}^{-1}$ for high tensile stresses (around $120 \mathrm{MPa}$ ).

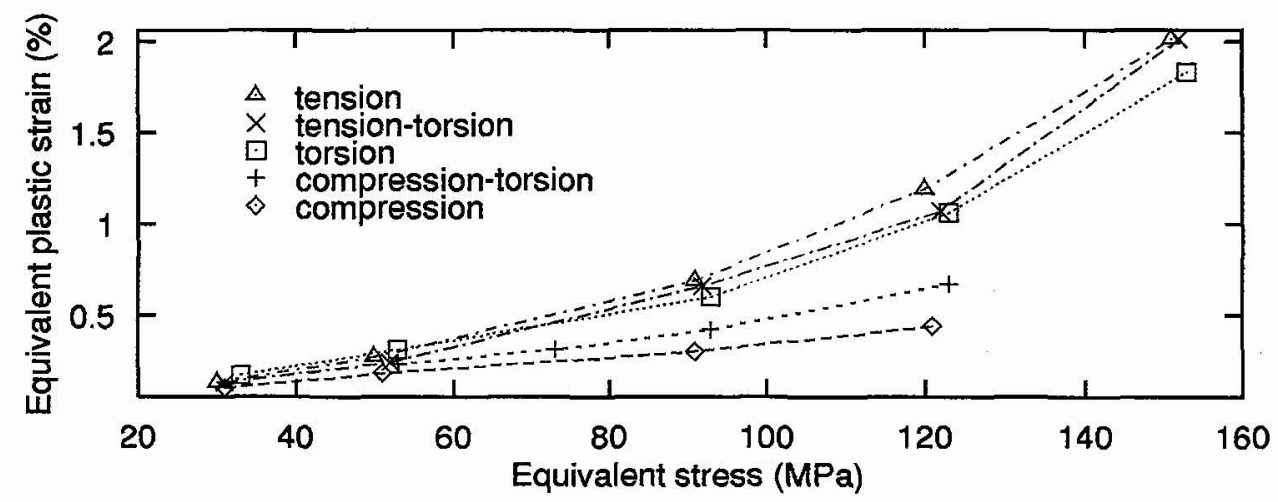

Figure 3: Total amount of translomation plasticity for various loading states (von Mises equivalents) 


\subsection{Direction of the transformation-induced plasticity flow in the stress plane}

Transformation-induced plastic flow rate is usually assumed to be collinear to the components of the deviatoric part of the stress tensor, denoted by $s_{\mathrm{ij}}$. This dependency is consistent with the use of the von Mises equivalent and of the normality assumption as detailed in [9]. As the stresses are kept constant during the transformation, the flow direction is constant and the rate equations can be integrated along the transformation path, so that the equivalent plastic strain for transformation-induced plasticity and the components of the transformation-induced plasticity strain should be related by:

$$
\begin{gathered}
\varepsilon_{11}^{p l}=\varepsilon_{c q}^{p l} n_{11} ; \varepsilon_{l 2}^{p l}=\varepsilon_{v q}^{p l} n_{12} \\
\text { with : } n_{i j}=\partial \sigma_{e q} / \partial \sigma_{i j}=(3 / 2) s_{i j} / \sigma_{c q}
\end{gathered}
$$

The values obtained in tension-shear and in compression-shear are reported in Table 2. For most of the cases, the assumption of a von Mises type flow seems to be reasonable within a first approximation, the agreement being better in tension-torsion than in compression-torsion.

Nevertheless, it can be noticed that the axial component seems to be a little too low. This point requires further investigations.

\begin{tabular}{|c|c|c|c|}
\hline$\sigma_{\mathrm{eq}}\left(\mathrm{MP}^{\mathrm{a}}\right)$ & $\varepsilon_{\mathrm{c} j}^{\mathrm{pl}}(\%)$ & $\varepsilon_{11}^{\mathrm{pl}} /\left(\varepsilon_{\mathrm{c}}^{\mathrm{pl}} \mathrm{n}_{11}\right)$ & $\varepsilon_{12}^{\mathrm{p}} /\left(\varepsilon_{\mathrm{cq}}^{\mathrm{pl}} \mathrm{n}_{12}\right)$ \\
\hline $\mathrm{T} 31$ & 0.13 & 0.98 & 1.01 \\
$\mathrm{~T} 52$ & 0.24 & 0.74 & 1.18 \\
$\mathrm{~T} 92$ & 0.66 & 0.97 & 1.03 \\
$\mathrm{~T} 122$ & 1.07 & 1.00 & 1.00 \\
$\mathrm{~T} 152$ & 2.01 & 0.97 & 1.03 \\
$\mathrm{C} 53$ & 0.23 & 1.01 & 0.99 \\
$\mathrm{C} 73$ & 0.31 & 0.89 & 1.09 \\
$\mathrm{C} 93$ & 0.42 & 0.89 & 1.09 \\
$\mathrm{C} 123$ & 0.67 & 0.83 & 1.14 \\
\hline
\end{tabular}

Table 2: Comparison of the flow dircetion with von Mises assumption in tunsion-shear (T) with $\sigma_{11}=\sigma_{12} \sqrt{3}$ and in compression-shear $(C)$ with $\sigma_{11}=-\sigma_{12} \sqrt{3} ;\left(\varepsilon_{i 1}^{p i}\right)^{2}=\left(\varepsilon_{11}^{p}\right)^{2}+(4 / 3)\left(\varepsilon_{12}^{p}\right)^{2}$.

\subsection{Relation between transformation induced plasticity and the transformation rate}

It was experimentally observed that the cooling of a specimen loaded in torsion does not induce any significant axial flow. Having in hand at tension-torsion extensometer, it is then possible to evaluate in a continuous way the volume fraction transformed from the axial measurement, and to get the transformationinduced plasticity from the shear component. Figure 4 shows the measured volume fraction as a function of temperature. If this result is now reported against the trinsfomation plasticity measured in shear, figure 5 is obtained. Uswally, two fommlations are used concurently to model the relation between the martensite volume fraction and the transfomation plasticity, either parabolic $[6,7,1], 12]$ or more complex [8]. These are expressed according to the lollowing formulae, where $\gamma$ stands for the shear transformation-induced plasticity, and $\mathrm{z}$ for the volume fraction of martensite:

$$
\begin{aligned}
& \gamma(z)=(2-z) z \gamma(z=1) \\
& \gamma(z)=(1-\ln (z)) z \gamma(z=1)
\end{aligned}
$$

Both of them seem to be acceptable, the first one being better for the higher loadings, the second one for the smaller ones. 


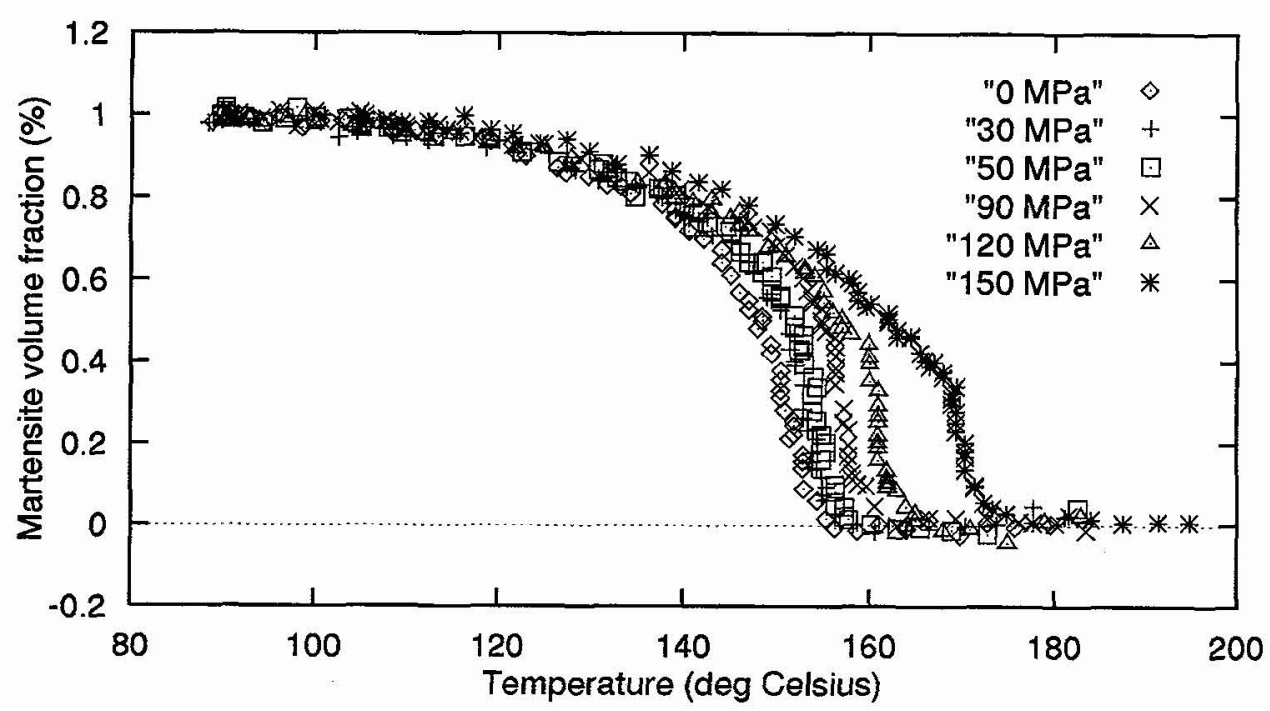

Figure 4: Measurement of the martensite volune fraction from the axial displacement on a torsion Joaded specimen
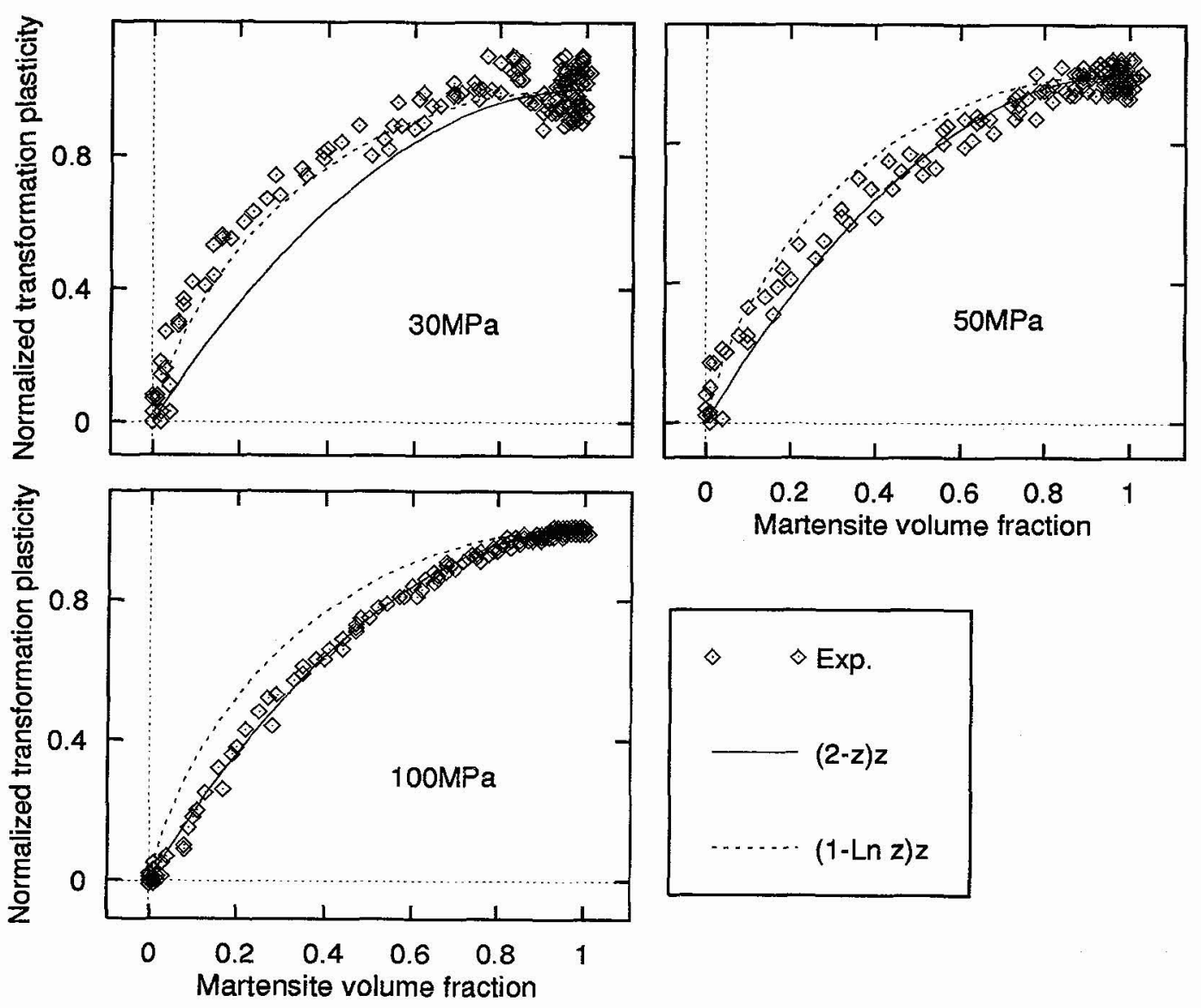
Martensite volume fraction

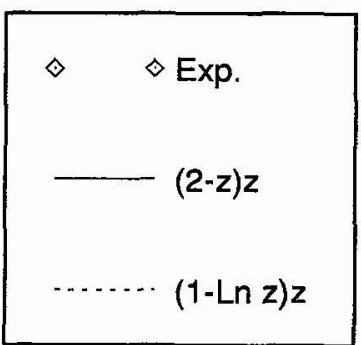

Figure 5: Scaling fackor betwen transfomation plastcily and mamensite volume fraction 


\title{
5.5 Evaluation of internal stresses
}

\begin{abstract}
Although the evaluation of the nomality rule with respect to at von Mises surface centred at the origin might be a first approximation, the tests shown in this section demonstrate that a substantial kinematic effect is present. These results suggest therefore that internal stresses must be introduced to describe the observed phenomena, as proposed in $19 \mid$. These internal stresses are related with transformation-induced plasticity and with classical plastic deformation.
\end{abstract}

\subsubsection{Internal stresses due to transformation-induced plasticity}

In the tests made under a torsional loading involving a first stress level of $120 \mathrm{MPa}$ and several unloading steps, it was found that the internal stress level for $50 \%$ transformation is about $60 \mathrm{MPa}$. That means that a $60 \mathrm{MPa}$ unloading does stop the transformation-induced plasticity. For larger unloadings, the sign of the plastic flow is changed, that is one comes from a tensile transformation plasticity flow under $120 \mathrm{MPa}$ to a compressive flow if the stress level reaches $30 \mathrm{MPa}$ for instance.

The existence of an internal stress wats also confirmed under tension loading. In the test which started under a $120 \mathrm{MPa}$ tension loading followed by a complete unloading, the transformation plasticity flow at zero load was negative.

This observation makes the modeling more complex. Specially, coming back to the normality rule discussed in section 5.3, it should be underlined that, due to the presence of an internal stress, the transformation-induced plasticity increment should now be collinear to the deviator of the effective stress instead of the stress itself. This assumption is consistent with the previous conclusions concerning the normality rule, to the extent that one maly reasomably postulate that the internal stress generated by the flow has the same direction as the applied stress, when the loading is constant.

\subsubsection{Internal stresses due a classical plasticity}

After four prehardening cycles in altemate lorsion made in the austenitic phase, the strain and the stress are set to zero by an appropriate unloalding path. When the last maximum (resp. minimum) of this loading is in positive torsion (resp. in negative torsion), the resulting internal stress is positive (resp. negative). This internal stress interacts with transformation plasticity : it follows for instance that the presence of prehardening:

- induces a plastic flow without applied load, whose direction depends on the prehardening sequence,

- (i) strongly decreases the amount of transformation plasticity if the load applied for performing the transformation plasticity has the same sign as the last loading of the cyclic history in the prehardening period, but (ii) does not affect significiantly the same variable for the opposite case, that means that in a model it might be necessary to couple the evolution of both variables.

Figure 6 illustrates this effect in at strian-stress plane. The four prehardening cycles are drawn. After total unloading at zero stress, it wis. found that the trunsformation plasticity flow was negative. Transformation plasticity depends then on a negative "effective stress", computed as the difference between zero (the applied stress) and a positive value coming from the first level.

Additional studies will precise quantitatively the levels of the internal stresses relating with transformationinduced plasticity and with classical plasticity, as a function of strain and temperature history, but, at the present time, one can consider that their presence is clearly established.

\section{DISCUSSION}

The evolution of the transfomation-induced plasticity strain is clatssically considered as driven by the rate of phase change, $\mathrm{dz}$, and proportional to a tuncrion of the degree of transformation, $f(z)$. The orientation of the strain increment $d \varepsilon_{i j}^{p l}$ is given by the deviatoric part of the applied stress $s_{i j}$ :

$$
d \varepsilon_{i j}^{p l}=f(z) s_{i j} d z
$$

As a first point, the present study shows that the usual formulations for the function $\mathrm{f}$ are acceptable. The dependency between the strain increment and the deviator seems to be more questionable. Two facts disagree with this expression: 


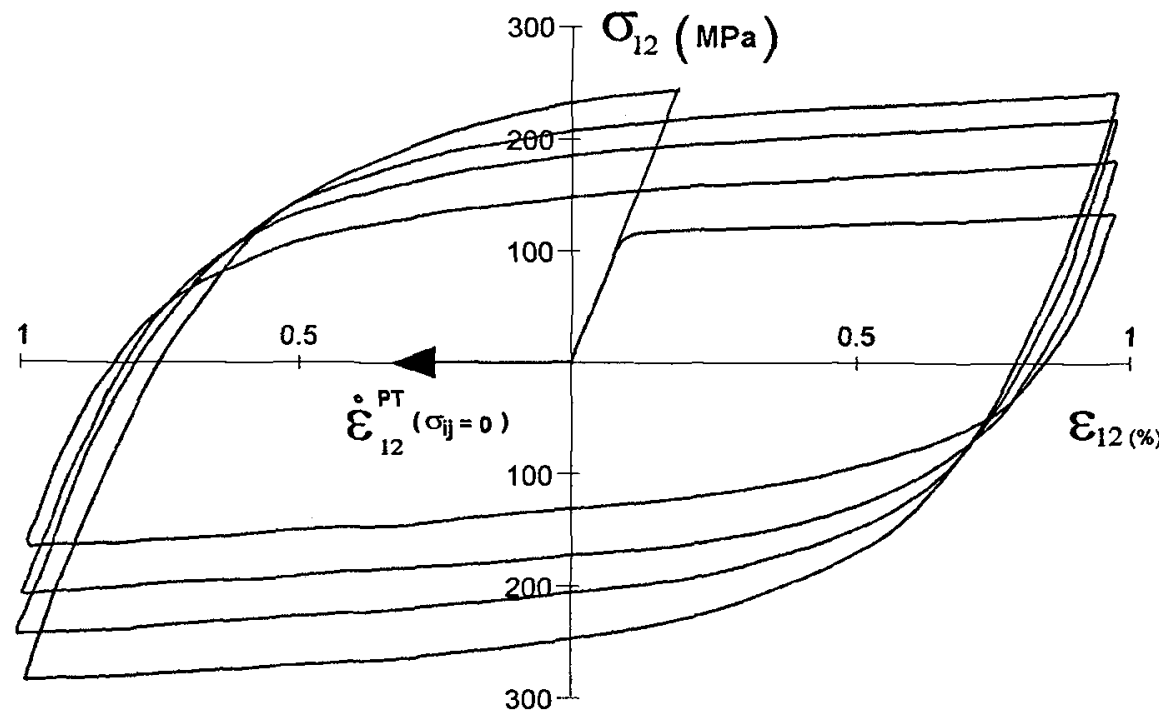

Figure 6: Example of a negative uansiomation plasticily llow for \%ero load after a cyclic prehardening stopped during the tension going branch

(i) the results strongly suggest that internal stresses must be introduced, i.e. a tensorial variable $\mathrm{X}^{\mathrm{p}}$ for representing the Bauschinger effect in clissical plasticity, and a tensorial variable $X^{\text {pl }}$ for the transformation induced plasticity. A correct model should thus lake info account the fact that the induced plastic flow produces material hardening, as assumed in 19$\}$. During the progression of the transformation, this induced plastic flow is related to the modification by the macroscopic stress of the plastic field around the martensitic plates, or to the stress-assisted geometrical orientation of the platelets themselves. For transformation induced plasticity as for classical plasticity, the origin of the hardening is "written" in the dislocation populations, so that it is easy to understand that the two internal stresses should be coupled. The present study allowed us to verify that classical plasticity affects the transformation-induced plasticity. The reverse effect is probably present, it could be shown by tests with a special temperature history, involving a cooling period to partially transform the austenite, followed by a rapid heating and the application of a cyclic loading: due to the re-heating, the transformation is stopped, and the mechanical loading provides a mechanical measurement of the internal stress state;

(ii) in addition, we demonstrated that plastic flow for a complete phase transformation is a non linear function of the applied stress and that lension has a larger effect than compression on the transformationinduced plasticity. This effect can be explained neither by the expression proposed in eq. 4 nor by the introduction of an internal stress. Other ingredients should then be used as the trace of the stress tensor, $I_{1}$. A possible solution would be to have the effect of the stress included in the intensity of the flow, that is the function $f$ should depend not only on $z$, but also on the two invariants $I_{1}$ and $J_{2}$ of the stresses (eq. 5).

$$
\mathrm{d} \varepsilon_{i j}^{p t}=f\left(z, \sigma_{i j}\right) s_{i j} d z
$$

In fact, as long as an internal stress has to be intreduced, the transformation plasticity flow will be expressed as a function of the effective stress, the component of which are $\sigma_{i j}-X_{i j}^{p t}$. A model has been proposed to fulfil the first requirements (i), with two interacting internal stresses [9!. The extension of this model to take into account the point (ii) is in progress (based on the formalism proposed in [9]). 


\section{CONCLUDING REMARKS}

A certain number of new elements conceming a comprehensive experimental study of transformationinduced plasticity are reported and analyzed. The tests were made under multiaxial loading and relatively high stress levels. The classical assumptions concerning the scaling factor $f(z)$ and the plastic flow direction seem to be reasonable. The most important points exhibited in the study are:

- the asymmetric effect of tension and compression load, which has never been observed previously on a steel,

- the non linear dependency of the transformation-induced plastic flow versus stress,

- the presence and the interaction of internal stresses associated with both transformation-induced plasticity and classical plasticity.

\section{Acknowledgements}

The authors would like to acknowledg̣e linancial suppont from institut de Recherche de la SIDérurgie (IRSID) and from Aubert\&Duval.

\section{References}

[1] Marketz F., Fischer F.D., Met. Trans., 26A (1995) 267-278.

[2] Magee C.L., Ph. D. Thesis, Carnegie Melon University, 1966.

[3] Abrassart F., "Influence des transformations martensitiques sur les propriétés mécaniques des alliages du système Fe-Ni-Cr-C", Thèse Université de Nancy I, 1972.

[4] Greenwood G.W., Johnson R.H., Proc. Royal Society, London, A283, 403-422.

[5] Gautier E., Simon A. Beck G., Actal Metall., 35, 1367.

[6] Giusti J., "Contraintes et déformations résiduelless d'origine thermique, application au soudage et à la trempe des aciers", Thèse Université de Paris VI, 1981.

[7] Leblond J.B., Mottet G., Devaux J., Devaux J.C., "Mathematical Models for Description of Anisothermal Phase Transformations in Steel and their Consequences on the Plastic Behaviour", Int. Symp. in the Calculation of Internat Stresses in Heat Treatment of Merallic Materials, Linkoping, Sweden, (1984) 191-220.

[8] Leblond J.B., Devaux J., Devaux J.C., Int. J. Plasticity, 5 (1989) 551-572.

[9] Videau J.C., Cailletaud G., Pinealu A., Journal de Physique III, 3 (1994) 227-232.

[10] Patel J.R., Cohen M., Acta Metall., I (1953) 531.

[11] Desalos Y., "Comportement dilatométrique et mécanique de l'austénite métastable d'un acier A533", IRSID Report $95349401,1981$.

[12] Denis S.; Gautier E. Simon A., Beck G., "Stress Phase Transformation Interactions: Basic Principles, Modelization and their Role in the Calculation of Internal Stresses", Int. Symp. in the Calculation of Internal Stresses in lleat Treatment of Metallic Materials, Linkoping, Sweden, (1984) 157190. 